Original article

\title{
Efficacy of Cinnamomum cassia Blume. in age induced sexual dysfunction of rats
}

\author{
Sumanta Kumar Goswami ${ }^{\mathrm{a}, *}$, Mohammed Naseeruddin Inamdar ${ }^{\mathrm{a}}$, Rohitash Jamwal ${ }^{\mathrm{b}}$, \\ Shekhar Dethe ${ }^{\mathrm{b}}$ \\ a Department of Pharmacology, Al-Ameen College of Pharmacy, Bangalore 560027, India \\ ${ }^{\mathrm{b}}$ Bioassay Lab, Research and Development Centre, Natural Remedies Pvt. Ltd., Bangalore 560100, India
}

\section{A R T I C L E I N F O}

Article history:

Received 16 September 2013

Accepted 1 November 2013

Available online 9 December 2013

\section{Keywords:}

Cinnamomum cassia

Corpus cavernosum

Aged rat

Sexual dysfunction

Sperm parameters

\begin{abstract}
A B S T R A C T
Objective: Cinnamomum cassia has been suggested in Ayurveda for the management of sexual dysfunction. This research work was conducted to shed some light on the mechanism of action of the extract, and evaluate the efficacy of its methanol extract in age induced sexual dysfunction in male Wistar rats. Secondary objective of the project was to study the effect of treatment on sperm parameters and smooth muscle:collagen level in rat penile tissue.

Methods: Young and aged male rats were treated with methanol extract of Cinnamomum cassia at a dose of $100 \mathrm{mg} / \mathrm{kg}$ and sexual behavior was observed on 28th day in presence of female rats in estrous phase. Sildenafil was used as standard medicine. Effect of treatment was studied on epididymal sperm parameters, and Massons trichrome staining of rat penile tissues was performed to know the level of smooth muscle:collagen.

Results: The treatment significantly increased sexual function in aged rats that had decreased in comparison to young rats, but did not have any significant effect on sperm count, live and defective sperm percentage. However, treatment induced an increase in smooth muscle level and a decrease in collagen level in the aged rat penile tissue in comparison to that of age matched control.

Conclusion: Based on our studies, we found that Cinnamomum cassia extract was effective in management of sexual dysfunction in aged rats and hence we propose a possible mechanism of action for Cinnamomum cassia which could be responsible for restoring sexual activity in aged rat.
\end{abstract}

Copyright @ 2013, InPharm Association, Published by Reed Elsevier India Pvt. Ltd. All rights reserved.

\section{Introduction}

Erectile dysfunction (ED), a male sexual dysfunction is the 'inability of the male to attain and maintain erection of the penis sufficient to permit satisfactory sexual intercourse'. It is a marker of cardiovascular disorder, decreases quality of life, affects elderly males, smokers, and those with diabetes and high blood pressure. ${ }^{2,3}$

Among the many treatment options available, a cGMP specific phosphodiesterase inhibitor, sildenafil, is commonly used. ${ }^{3}$ Others include dopamine receptor agonist (apomorphine), selective serotonine re-uptake inhibitor (trazodone), alpha-2 receptor blocker (yohimbine), and non-specific phosphodiesterases inhibitor (papaverine). Sildenafil is a first line of medicine for increasing erectile function and was used as standard medicine in our studies. It prevents degradation of cGMP, which regulates blood flow in the

\footnotetext{
* Corresponding author. Tel.: +910 8022113861.

E-mail address: sumantag@gmail.com (S.K. Goswami).
}

penis. Many other enzymes and their inhibitors have been implicated in the management of ED including Rho-kinase 2 (ROCK-II). ${ }^{4,5}$ Methanol and successive aqueous extract of Cinnamomum cassia have been reported to inhibit ROCK-II where methanol extract was found to be more potent. ${ }^{6}$

Ayurveda, an ancient Indian system of alternative medicine has suggested use of herbs for the management of sexual dysfunction. ${ }^{7}$ A number of studies on Indian herbal extracts have reported an increase in sexual function in normal, castrated and diabetic rats. ${ }^{8-12}$ However, to best of our knowledge, no modern scientific literature is available for the efficacy of Cinnamomum cassia in age induced sexual dysfunction. The current research work was carried out to study the efficacy of Cinnamomum cassia methanol extract (CCME) in age induced sexual dysfunction and understand the possible mechanism of its action by which the extract ameliorates the condition. In addition, the effect of CCME was studied on sperm parameters and smooth muscle:collagen level in aged rat penile tissue. 


\section{Materials and methods}

\subsection{Plant material and extraction}

Dried bark of Cinnamomum cassia was purchased from Amrutha Keshari Ayurvedic store, Bangalore and authenticated by Dr. P. Santhan (Taxonomist at Natural Remedies Private Limited/NRPL, Bangalore). Specimen sample was stored at NRPL repository with specimen number NPL/CD/169. Methanol extract of Cinnamomum cassia (CCME) was prepared as described previously. ${ }^{13}$

\subsection{Chemicals and materials}

Tween 20 and Sodium chloride (HiMedia Labs, India); Diethyl stilbestrol (Penta Pharmaceuticals, India); progesterone (Sun Pharmaceutical Ind. Ltd., India); Triton ${ }^{\mathrm{TM}} \mathrm{X}-100$ and merthiolate (Sigma Aldrich Co., USA); and Sildenafil (Watson Pharma India Ltd., India) were procured. All other reagents used in the study were of analytical grade.

\subsection{Animals}

Young (6 month old) male and female Wistar rats weighing 200-250 g and aged (24 months old) male rats weighing 300$350 \mathrm{~g}$ were used. The animals had free access to food and drinking water, and were maintained at $25 \pm 1{ }^{\circ} \mathrm{C}$. Study protocol was reviewed and approved by institutional animal ethics committee before the start of the work.

\subsection{Acute toxicity study}

Acute toxicity study was performed on female mice in accordance with the Organization for Economic Cooperation and Development guidelines for the testing of chemicals, (OECD 425: Acute Oral Toxicity-Up-and-Down-Procedure), 2006.

Three month old female mice weighing $27 \pm 3 \mathrm{~g}$ were dosed with $2 \mathrm{~g} / \mathrm{kg}$ body weight of Cinnamomum cassia methanol extract. Mice were fasted for $4 \mathrm{~h}$ before dosing and food was allowed only after $2 \mathrm{~h}$ of treatment. The extract was triturated using mortar and pestle with distilled water containing $1 \%$ Tween 20 . A vehicle control (1\% Tween 20) group was maintained.

Animals were observed at least once during the first $30 \mathrm{~min}$ after dosing, periodically during the first $24 \mathrm{~h}$ (with special attention given during the first $4 \mathrm{~h}$ ), and thereafter, daily for a total period of 14 days for any adverse event (time of onset, length of recovery period).

\subsection{Sexual behavior study}

Male Wistar rats were divided into 4 groups of six rats each i.e. group I (young rat treated with 1\% Tween 20 in water), group II (aged rat treated with 1\% Tween 20 in water), group III (aged rat treated with $100 \mathrm{mg} / \mathrm{kg}$ body weight CCME) and group IV (aged rat treated with $20 \mathrm{mg} / \mathrm{kg}$ body weight sildenafil). CCME and sildenafil were suspended in water containing $1 \%$ Tween 20 and administered orally. Sexual behavior study was performed as described in published literature. $^{8-13}$ A week before start of study, male rats were sexually trained in presence of female rats for 3 days. Ovariectomized female rats $^{14}$ for the study were brought to estrous phase by administration of diethyl stilbestrol $(1 \mathrm{mg} / \mathrm{kg}$, p.o, administered 2 days before the study) and progesterone ( $5 \mathrm{mg} / \mathrm{kg}$, s.c., administered $6 \mathrm{~h}$ prior to the study). Male rats were dosed orally for 28 days and sexual behavior was observed on 28th day for $30 \mathrm{~min}$ in the evening. Following sexual behavior parameters of male rats were observed in presence of female rat in a wooden box $(45 \times 50 \times 35 \mathrm{~cm})$ covered with glass lid and illuminated with red light.

Mount latency (ML): time from the introduction of female into the cage of the male up to the first mount.

Intromission latency (IL): time from the introduction of the female up to the first intromission by the male.

Mount frequency (MF): number of mounts before ejaculation.

Intromission frequency (IF): number of intromission before ejaculation.

Ejaculation latency (EL): time from the first intromission of a series up to the ejaculation.

Post-ejaculatory interval (PEI): time from the first ejaculation up to the next intromission by the male.

\subsection{Sperm analysis}

After completion of sexual behavior study, male animals were anesthetized with ether and sacrificed by cervical dislocation. Left epididymis and shaft of penile tissue from each rat was excised. Epididymis was used for sperm parameter study whereas shaft of penile tissue was kept in $7 \%$ formalin saline solution for histopathology.

Sperm count and analysis was performed by the methods as reported earlier. ${ }^{13,15-18}$ Briefly, the epidydimises were transferred to beakers containing $30 \mathrm{~mL}$ of saline-triton-merthiolate solution (saline solution containing $0.05 \%$ triton- $\mathrm{X}$ and $0.01 \%$ merthiolate) and teased with surgical blade. Sperms were allowed to diffuse into the solution for $15 \mathrm{~min}$ and volume was made up to $50 \mathrm{~mL}$ with distilled water. Subsequently, $0.5 \mathrm{~mL}$ of $1 \%$ eosin Y solution was added to the sperm solution and mixed well. $10 \mu \mathrm{L}$ of this sperm solution was placed on Neubauer chamber for sperm count study. Sperm heads were counted using light microscope (Olympus CX41, Olympus, USA; magnification: $200 \times$ ) and mean sperm count in all 4 corner square were counted using the following formula.

No. of sperms per caudal epididymis

$$
=\frac{\text { Mean count } \times 50(\text { total volume })}{0.01 \times 0.01(\text { Volume of counting chamber })}
$$

Live sperm ratio was calculated by the following formula.

$$
\text { Live sperm percentage }=\frac{\text { Total number of live sperm }}{\text { Total number of sperms counted }} \times 100
$$

Defective sperms (coiled sperms, tail less sperms, sperms with bent neck, midpiece and tails) were observed and percentage was calculated using the following formula.

$$
\text { Defective sperm percentage }=\frac{\text { Total defective sperms counted }}{\text { Total number of sperms counted }} \times 100
$$




\subsection{Penile tissue histopathology}

Excised shaft of penile tissues were fixed in $7 \%$ formalin saline and paraffin blocks of the tissue were prepared. Paraffin sections of tissue ( $5 \mathrm{~mm}$ thickness) were taken and Masson's trichrome staining was performed for determining smooth muscle:collagen level using a standard protocol. ${ }^{13,19,20}$ Briefly, the tissues were hydrated and dipped in bouin's fluid for $12 \mathrm{~h}$ at $27^{\circ} \mathrm{C}$. The tissues were then washed and rinsed in distilled water followed by staining in Wigards iron haematoxylene for $10 \mathrm{~min}$. The tissues were subsequently washed and rinsed in distilled water followed by staining in Biebrich scarletacid fuchsin for $5 \mathrm{~min}$. After rinsing with distilled water, tissues were treated with phosphomolybdic-tungstic acid solution followed by staining in aniline blue for $3 \mathrm{~min}$. Further, the tissues were rinsed with distilled water followed by rinsing with dilute acetic acid for 5 min. The tissues were then dehydrated, cleared in xylene and mounted in DPX (contains a neutral plastic resin dissolved in xylene and containing di-n-butyl phthalate as a plasticizer). The tissues were observed under light microscope (Nikon, Japan; magnification: $20 \times$ ) fitted with Nikon digital camera (model number: DS-Ri1).

\subsection{Statistical methods}

Effect of vehicle (1\% Tween 20), CCME and sildenafil on sexual behavior and sperm parameters are expressed as mean \pm standard error of mean (SEM). Statistical significance was calculated using one way ANOVA followed by Tukey's multiple comparison tests using GraphPad ${ }^{\circledR}$ Prism version 5.

\section{Results}

\subsection{Acute toxicity study}

CCME was found to be safe up to $2 \mathrm{~g} / \mathrm{kg}$ body weight in mice and a single dose of the extract was selected for in vivo study based upon a pilot study.

\subsection{Sexual behavior study}

Sexual dysfunction was observed in aged rats which was evident by increase in ML, IL, and PEI and decrease in MF, IF and EL in

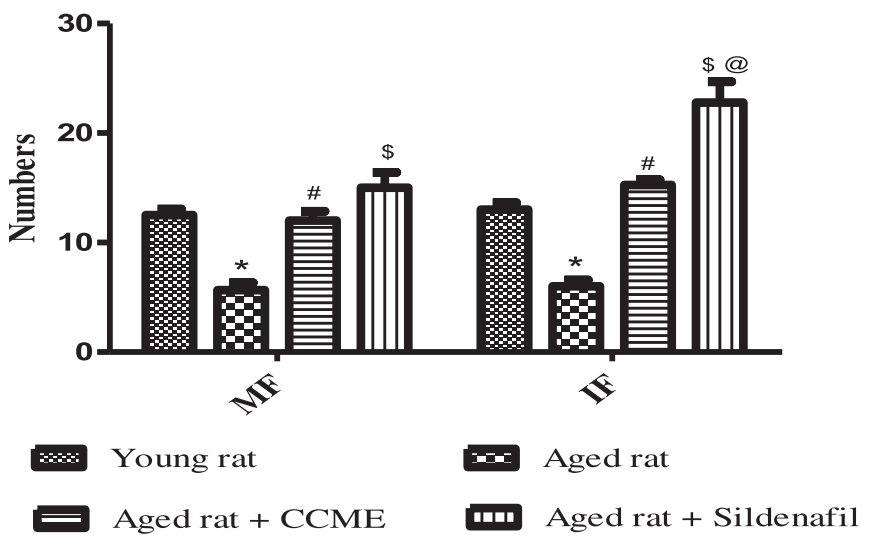

Fig. 2. Effect of treatment on Mount Frequency (MF) and Intromission Frequency (IF) of male rats. MF and IF of aged rats treated with vehicle were decreased significantly $\left({ }^{*} p<0.01\right)$ in comparison to young rats fed with vehicle. Treatment of Cinnamomum cassia methanol extract/CCME $\left({ }^{\#} p<0.01\right)$ and sildenafil $\left({ }^{\$} p<0.001\right)$ increased MF and IF significantly in comparison to age matched control rat fed with vehicle. Effect of sildenafil was better than CCME $\left({ }^{@} p<0.01\right)$.

comparison to young rats. Treatment with CCME and sildenafil restored sexual dysfunction of aged rats (Figs. 1 and 2).

\subsection{Sperm analysis}

With age, the total sperm and live sperm count decreased and percent of defective sperm increased in aged rats in comparison to that of young rats. CCME treatment decreased percent of dead sperm and defective sperm in aged rat while it increased live sperm count. CCME treatment decreased total sperm count with comparison to aged rat treated with vehicle. CCME and sildenafil treatment did not show any significant effect on sperm count, live sperm percentage and defective sperm percentage (Fig. 3).

\subsection{Penile tissue histopathology}

Smooth muscle:collagen ratio was approximately $1: 10$ in young rat penile tissue (corpus cavernosum smooth muscle). A decreased smooth muscle level and an increased collagen level in corpus cavernosum smooth muscle (CCSM) were found in aged rats in

Efficacy of Cinnamomum cassia Blume. in age induced sexual dysfunction of rats.

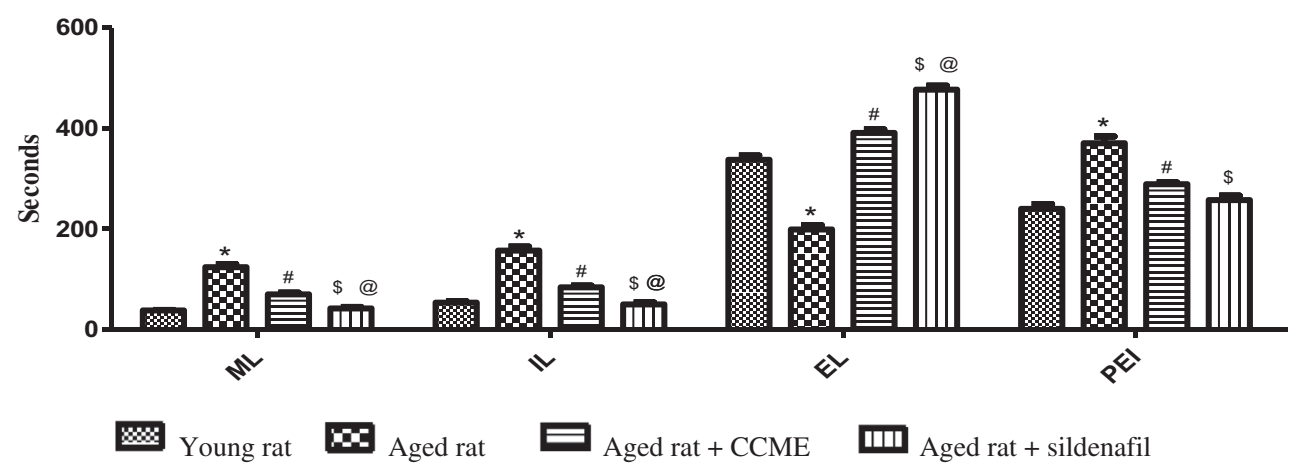

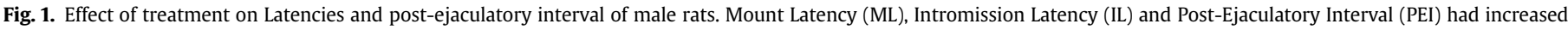

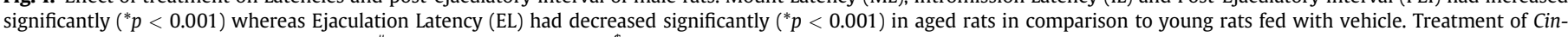

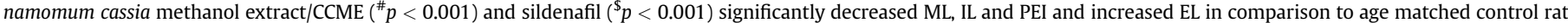

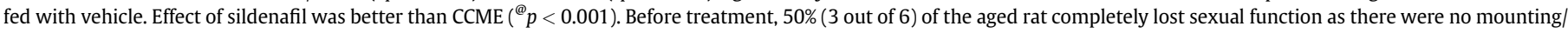
intromission till 20th minutes. After treatment, 4 and 5 rats responded to CCME and sildenafil, respectively. 

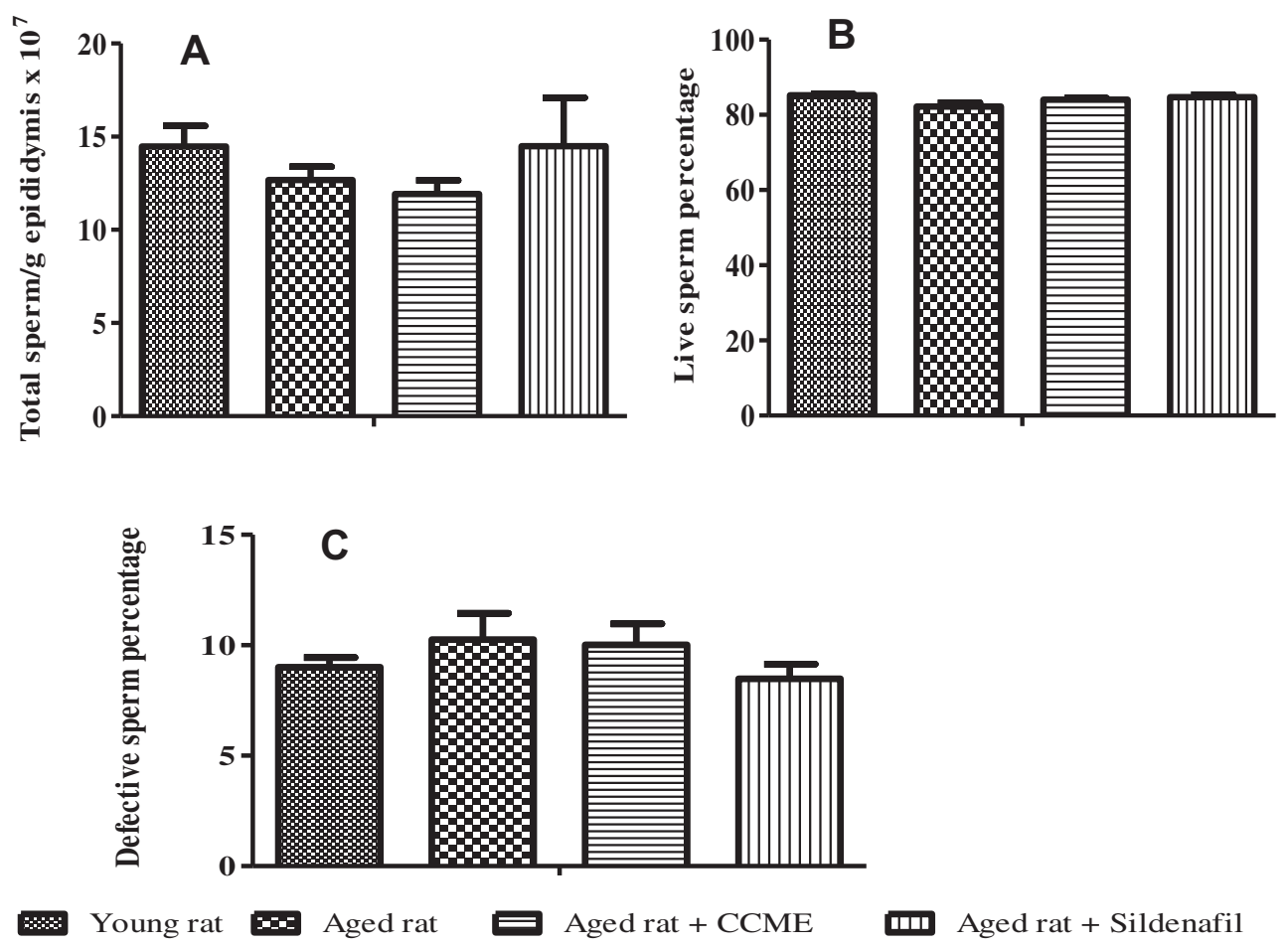

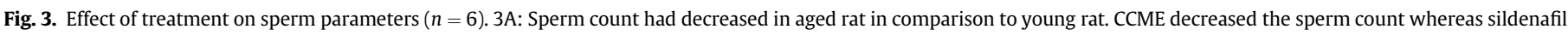

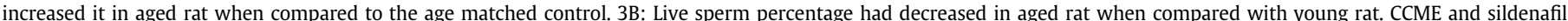

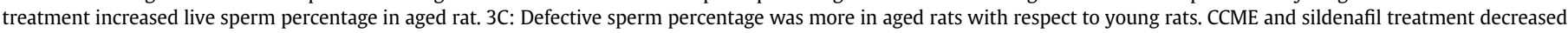
defective sperm percentage in aged rats. CCME and sildenafil did not result in any significant effect on sperm parameters.

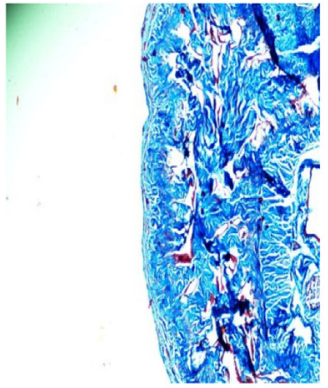

Young rat

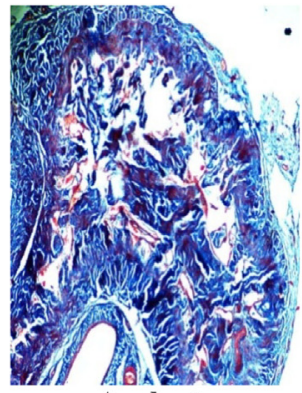

Aged rat

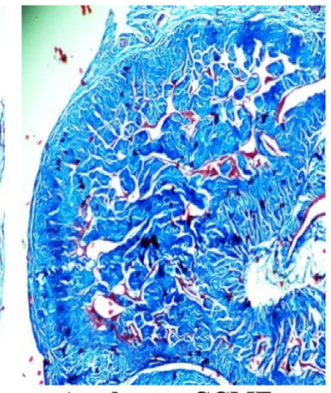

Aged rat + CCME

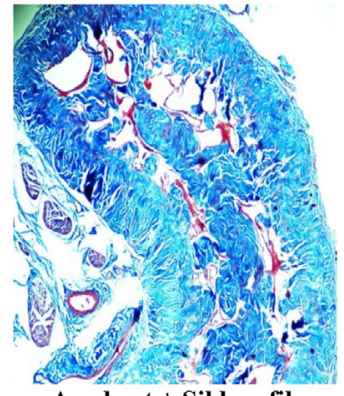

Aged rat + Sildenafil

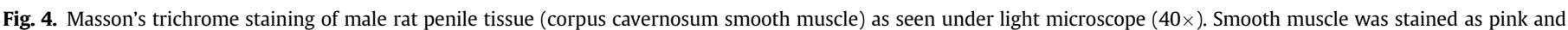

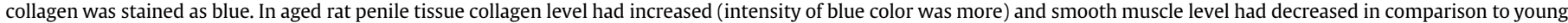

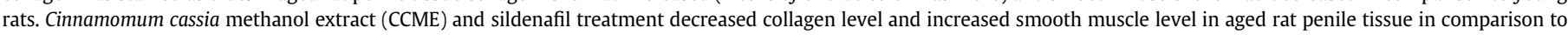
age matched control.

comparison to that of young rats. CCME and sildenafil treatment increased smooth muscle level in aged rat penile tissue (Fig. 4).

\section{Discussion}

CCME treatment in aged rats increased sexual function which otherwise exhibited a decreased sexual function as compared to young rats. ML represents sexual motivation and decrease in ML by CCME indicates that it increased sexual motivation. Similarly, it has been suggested that number of intromission (IF), time taken for ejaculation (EL) and resting period between two consecutive sexual period (PEI) depend on degree of erection, duration of erection and time taken for regaining erection after ejaculation respectively. ${ }^{21,22}$ CCME increased IF and EL; and decreased PEI therefore confirming erectogenic potential of CCME. Increase in Rho-kinase activity in aged rat penile tissue was proposed to be responsible for sexual dysfunction in aged rat and ROCK-II inhibitors alleviated sexual dysfunction. ${ }^{23,24}$ Increased erectile function in aged rat treated with CCME could be attributed to Rho-kinase 2 (ROCK-II) inhibition and resultant increase in myosin light chain level in corpus cavernosum smooth muscle of penile tissue. ${ }^{6,23,24}$

Nitric oxide synthase (NOS) generates nitric oxide (NO) that stimulates soluble guanylyl cyclase (sGC) to produce cyclic guanosine monophosphate (cGMP). The second messenger relaxes CCSM that is essential for erection. ${ }^{25,26}$ eNOS uncoupling and subsequent production of reactive oxygen species (ROS) has been reported to be responsible for age related erectile dysfunction. ${ }^{27}$ Upregulation of NADPH oxidase was associated with downregulation of neuronal and endothelial nitric oxide synthase (NOS) in aged rat corpus cavernosum. Antioxidant (apocynin, a NADPH oxidase inhibitor) therapy normalized erectile function of middle aged rat. ${ }^{28}$ ROS have been reported to cause erectile dysfunction and this could be due to 


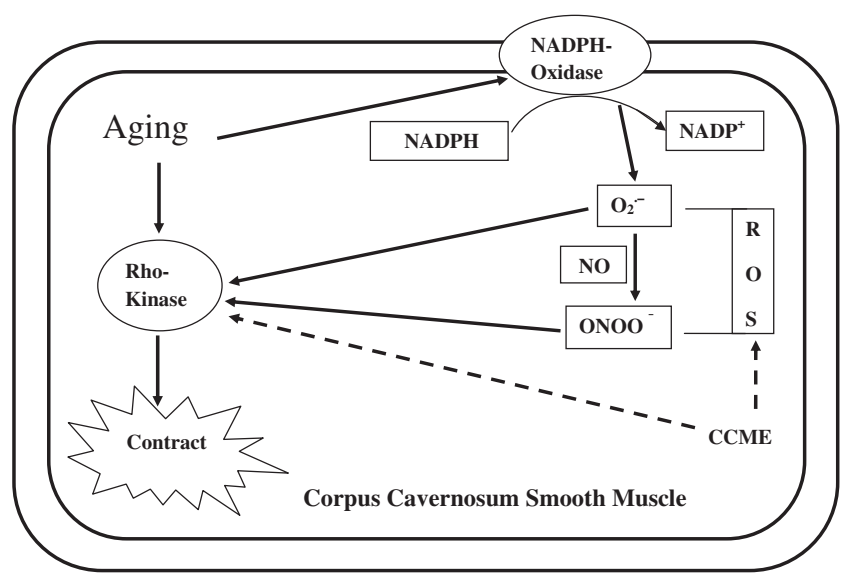

Fig. 5. Proposed mechanism of Cinnamomum cassia methanol extract (CCME) action on corpus cavernosum smooth muscle (CCSM) of aged rat penile tissue. Solid arrow represents stimulation whereas dotted arrow means inhibition. NO: nitric oxide, NADPH: reduced form of nicotinamide adenine dinucleotide phosphate, $\mathrm{NADP}^{+}$: nicotinamide adenine dinucleotide phosphate, $\mathrm{O}_{2}^{-}$: superoxide anion, $\mathrm{ONOO}^{-}$: peroxynitrite, ROS: reactive oxygen species. In aged rat penile tissue, Rho-kinase and NADPH oxidase activity increases. Rho-kinase contracts CCSM while NADPH oxidase generates ROS that activate Rho-kinase apart from damaging CCSM. CCME increases erectile function in aged rat penis by relaxing CCSM and protecting CCSM from oxidative damage. The extract inhibits Rho-kinase and controls level of ROS probably by inhibiting NADPH oxidase and/increasing antioxidant defense system.

stimulation of Rho-kinase activity. ${ }^{29,30}$ Rho GTPase/Rho-kinase pathway negatively regulates eNOS function through the inhibition of protein kinase B/Akt in human endothelial Cells. RhoA/Rhokinase suppresses eNOS in diabetic rat penis. ${ }^{31}$ Similar inhibition of eNOS by Rho-kinase could be possible in aged rat penis. In addition to Rho-kinase inhibition, antioxidant potential ${ }^{32}$ of Cinnamomum cassia could be responsible for increasing sexual function in aged rat (Fig. 5).

Oxidative stress decreases total sperm count and increases production of defective sperm in aged rat. Herbal extract having antioxidant potential is reported to increase live sperm percentage and decrease sperm morphological damage. ${ }^{33}$ Cinnamomum cassia was reported to possess antioxidant property ${ }^{32}$ and cinnamon bark oil at a dose of $100 \mathrm{mg} / \mathrm{kg}$ by gavage daily for 10 weeks to the rats significantly increased epididymal sperm concentration but insignificantly decreased abnormal sperm count and apoptotic germ cell count. ${ }^{34}$ Decrease in dead and defective sperm percentage in aged rat treated with CCME might be due to antioxidant potential of CCME. Administration of sildenafil to rats at $5 \mathrm{mg} / \mathrm{kg}$ for 120 days decreased sperm count and increased defective sperm percentage. ${ }^{35}$ However, 28 days of treatment of sildenafil at the same dose increased live sperm percentage and decreased defective sperm percentage in our study. Decrease in dead and defective sperm percentage in aged rats treated with sildenafil could be due to its antioxidant potential. ${ }^{36}$

Methanolic extract of Cinnamomum cassia increased the level of smooth muscle which was decreased in aged rat. Increase in sexual function of aged rat treated with CCME could be due to increase in smooth muscle level of CCSM. Administration of sildenafil at $20 \mathrm{mg} / \mathrm{kg} /$ day for 45 days increased smooth muscle:collagen ratio and smooth muscle cells in penile tissue of 20 months aged rat. ${ }^{19}$ We also observed a similar result that could be due to increased cGMP and NOS; and Rho-kinase inhibition in penile smooth muscle.

Based on our studies, we propose a mechanism by which Cinnamomum cassia extract might be alleviating sexual dysfunction (Fig. 5).

\section{Conclusion}

Cinnamomum cassia increased the sexual function in terms of sexual motivation and erectile function in aged rats. The increase in erectile function by CCME could be attributed to Rho-kinase inhibition, increase in smooth muscle:collagen ratio and mitigation of oxidative stress in rat penile smooth muscle. Increase in smooth muscle level in rat penile tissue might also be due to ability of Cinnamomum cassia to increase angiogenesis.

\section{Conflicts of interest}

All authors have none to declare.

\section{Acknowledgment}

A part of this work was funded by National Medicinal Plants Board (India) Grant (R\&D/KR-03/2009-10-NMPB). The authors acknowledge the help of Mr. Senthil Kumar A and Dr. Bharathi (Natural Remedies Private Limited) for the sperm characteristic study and reviewing manuscript respectively. Tissue processing and staining for histopathology was performed at Deepak Diagnostic Lab, Bangalore.

\section{References}

1. NIH Consensus Development Panel on Impotence. Impotence. JAMA. 1993;270: 83-90.

2. Burchardt M, Burchardt T, Anastasiadis AG, et al. Erectile dysfunction is a marker for cardiovascular complications and psychological functioning in men with hypertension. Int J Impot Res. 2001;13:276-281.

3. Carson CC. Erectile Dysfunction: evaluation and new treatment options. Psychosom Med. 2004;66:664-671.

4. Christianson DW. Arginase: structure, mechanism, and physiological role in male and female sexual arousal. Acc Chem Res. 2005;38:191-201.

5. Wingard CJ, Johnson JA, Holmes A, Prikosh A. Improved erectile function after Rho-kinase inhibition in a rat castrate model of erectile dysfunction. Am J Physiol Regul Integr Comp Physiol. 2003;284:R1572-R1579.

6. Goswami SK, Pandre MK, Jamwal R, Dethe S, Agarwal A, Inamdar MN Screening for Rho-kinase 2 inhibitory potential of Indian medicinal plants used in management of erectile dysfunction. J Ethnopharmacol. 2012;144:483-489.

7. Sharma PV. Charaka Samhita. 3rd ed. Vol. 2. Varanasi, India: Chaukhamba Orientalia; 1996.

8. Chauhan NS, Dixit VK. Effects of Bryonia laciniosa seeds on sexual behaviour of male rats. Int J Impot Res. 2010;22:190-195.

9. Ramachandran S, Sridhar Y, Sam SKG, et al. Aphrodisiac activity of Butea frondosa Koen. ex Roxb. extract in male rats. Phytomedicine. 2004:11:165-168.

10. Suresh S, Prithiviraj E, Prakash S. Dose- and time-dependent effects of ethanol extract of Mucuna pruriens Linn. seed on sexual behavior of normal male rats. J Ethnopharmacol. 2009;122:497-501.

11. Suresh S, Prakash S. Effect of Mucuna pruriens (Linn.) on sexual behavior and sperm parameters in streptozotocin-induced diabetic male rat. J Sex Med. 2012;9:3066-3078.

12. Gauthaman K, Adaikan PG, Prasad RN. Aphrodisiac properties of Tribulus terrestris extract (Protodioscin) in normal and castrated rats. Life Sci. 2002;71: 1385-1396.

13. Goswami SK, Inamdar MN, Pandre MK, Jamwal R, Dethe S. Erectogenic and aphrodisiac effects of Butea frondosa Koenig ex Roxb. in rats: involvement of enzyme inhibition. Evid Based Complement Alternat Med. 2013;2013: 874894.

14. Parhizkar S, Ibrahim R, Latiff LA. Incision choice in Laparatomy: a comparison of two incision techniques in ovariectomy of rats. World Appl Sci J. 2008:4:537-540.

15. Working PK, Hurtt ME. Computerized videomicrographic analysis of rat sperm motility. J Androl. 1987;8:300-337.

16. Seed J, Chapin RE, Clegg ED, et al. Methods for assessing sperm motility, morphology, and counts in the rat, rabbit, and dog: a consensus report. Reprod Toxicol. 1996; 10:237-244.

17. Ashby J, Tinwell H, Lefevre PA, Joiner R, Haseman J. The effect on sperm production in adult Sprague-Dawley rats exposed by gavage to bisphenol A between postnatal days 91-97. Toxicol Sci. 2003;74:129-138.

18. Saba AB, Oridupa OA, Oyeyemi MO, Osanyigbe OD. Spermatozoa morphology and characteristics of male Wistar rats administered with ethanolic extract of Lagenaria breviflora Roberts. Afr J Biotechnol. 2009;8:1170-1175.

19. Ferrini MG, Kovanecz I, Sanchez S, et al. Long-term continuous treatment with sildenafil ameliorates aging-related erectile dysfunction and the underlying corporal fibrosis in the rat. Biol Reprod. 2007;76:915-923.

20. Suresh S, Prakash S. Effect of Mucuna pruriens (Linn.) on oxidative stressinduced structural alteration of corpus cavernosum in streptozotocininduced diabetic rat. J Sex Med. 2011;8:1943-1956. 
21. Agmo A. Male rat sexual behavior. Brain Res Protoc. 1997;1:203-209.

22. Yakubu MT, Akanji MA, Oladiji AT. Male sexual dysfunction and methods used in assessing medicinal plants with aphrodisiac potentials. Pharmacog Rev. $2007 ; 1: 49-56$

23. Jin L, Liu T, Lagoda GA, Champion HC, Bivalacqua TJ, Burnett AL. Elevated RhoA/ Rho-kinase activity in the aged rat penis: mechanism for age-associated erectile dysfunction. FASEB J. 2006;20:536-538.

24. Rajasekaran M, White S, Baquir A, Wilkes N. Rho-kinase inhibition improves erectile function in aging male brown-Norway rats. J Androl 2005·26:182-188.

25. Trigo-Rocha F, Aronson WJ, Hohenfellner M, Ignarro LJ, Rajfer J, Lue TF. Nitric oxide and cGMP: mediators of pelvic nerve-stimulated erection in dogs. Am. Physiol. 1993;264:H419-H422.

26. Bivalacqua TJ, Burnett AL, Hellstrom WJG, Champion HC. Overexpression of arginase in the aged mouse penis impairs erectile function and decreases eNOS activity: Influence of in vivo gene therapy of anti-arginase. Am J Physiol Heart Circ Physiol. 2007;292:H1340-H1351.

27. Johnson JM, Bivalacqua TJ, Lagoda GA, Burnette AL, Musicki B. eNOS-uncoupling in age-related erectile dysfunction. Int J Impot Res. 2011;23:43-48.

28. Silva FH, Mónica FZ, Báu FR, et al. Superoxide anion production by NADPH oxidase plays a major role in erectile dysfunction in middle-aged rats: prevention by antioxidant therapy. J Sex Med. 2013;10:960-971.
29. Jones RW, Rees RW, Minhas S, Ralph D, Persad RA, Jeremy JY. Oxygen free radicals and the penis. Epert Opin Pharmacother. 2002;3:889-897.

30. Jin L, Ying Z, Webb RC. Activation of Rho/Rho kinase signaling pathway by reactive oxygen species in rat aorta. Am J Physiol Heart Circ Physiol. 2004;287: H1495-H1500.

31. Bivalacqua TJ, Champion HC, Usta MF, et al. RhoA/Rho-kinase suppresses endothelial nitric oxide synthase in the penis: a mechanism for diabetesassociated erectile dysfunction. Proc Natl Acad Sci U S A. 2004;101:9121-9126.

32. Chan S, Li S, Kwok C, et al. Antioxidant activity of Chinese medicinal herbs. Pharm Biol. 2008;46:587-595.

33. Suresh S, Prithiviraj E, Prakash S. Effect of Mucuna pruriens on oxidative stress mediated damage in aged rat sperm. Int J Androl. 2010;33:22-32.

34. Yüce A, Türk G, Ceribași S, Sönmez M, Ciftçi M, Güvenç M. Effects of cinnamon (Cinnamomum zeylanicum) bark oil on testicular antioxidant values, apoptotic germ cell and sperm quality. Andrologia. 2013;45:248-255.

35. Suresh S, Prithiviraj E, Venkatalakshmi N, et al. Long-term exposure of sildenafil citrate on sperm parameters in rat. Reprod Dev Biol. 2011;35: 435-439.

36. Perk H, Armagan A, Naziroglu M, et al. Sildenafil citrate as a phosphodiesterase inhibitor has an antioxidant effect in the blood of men. J Clin Pharm Ther. 2008;33:635-640. 